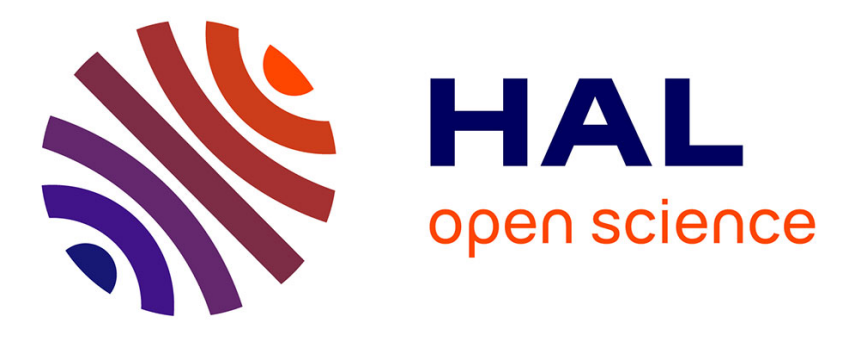

\title{
Benefits of proportionate selection in embodied evolution
}

\author{
Nicolas Bredeche, Jean-Marc Montanier, Simon Carrignon
}

\section{To cite this version:}

Nicolas Bredeche, Jean-Marc Montanier, Simon Carrignon. Benefits of proportionate selection in embodied evolution. Evolving Collective Behaviors in Robotics Workshop at GECCO 2017., 2017, Berlin, Germany. 10.1145/3067695.3082551 . hal-03314580

\section{HAL Id: hal-03314580 \\ https://hal.sorbonne-universite.fr/hal-03314580}

Submitted on 5 Aug 2021

HAL is a multi-disciplinary open access archive for the deposit and dissemination of scientific research documents, whether they are published or not. The documents may come from teaching and research institutions in France or abroad, or from public or private research centers.
L'archive ouverte pluridisciplinaire $\mathbf{H A L}$, est destinée au dépôt et à la diffusion de documents scientifiques de niveau recherche, publiés ou non, émanant des établissements d'enseignement et de recherche français ou étrangers, des laboratoires publics ou privés. 
archives-ouvertes

\title{
Benefits of proportionate selection in embodied evolution
}

\author{
Nicolas Bredeche, Jean-Marc Montanier, Simon Carrignon
}

\section{To cite this version:}

Nicolas Bredeche, Jean-Marc Montanier, Simon Carrignon. Benefits of proportionate selection in embodied evolution. Evolving Collective Behaviors in Robotics Workshop at GECCO 2017. Proceedings of the Genetic and Evolutionary Computation Conference Companion (GECCO), 2017, Berlin, Germany. 10.1145/3067695.3082551 . hal-03314580

\section{HAL Id: hal-03314580 \\ https: / hal.sorbonne-universite.fr/hal-03314580}

Submitted on 5 Aug 2021

HAL is a multi-disciplinary open access archive for the deposit and dissemination of scientific research documents, whether they are published or not. The documents may come from teaching and research institutions in France or abroad, or from public or private research centers.
L'archive ouverte pluridisciplinaire HAL, est destinée au dépôt et à la diffusion de documents scientifiques de niveau recherche, publiés ou non, émanant des établissements d'enseignement et de recherche français ou étrangers, des laboratoires publics ou privés. 


\section{Benefits of Proportionate Selection in Embodied Evolution: a Case Study with Behavioural Specialization}

\author{
Nicolas Bredeche* \\ Sorbonne Universités \\ UPMC Univ Paris 06, CNRS, ISIR \\ Paris, France F-75005 \\ nicolas.bredeche@upmc.fr
}

\author{
Jean-Marc Montanier \\ Softbank Robotics Europe \\ Paris, France \\ jmmontanier@softbankrobotics.com
}

\author{
Simon Carrignon \\ Barcelona Supercomputing Center \\ (BSC) \\ Barcelona, Spain \\ simon.carrignon@bsc.es
}

\begin{abstract}
We, as well as others, have already shown in previous works that reproductive isolation and a large population size are critical to achieve behavioral specialization in embodied evolutionary robotics. Here, we extend our previous work from [3] by experimentally demonstrating that fitness-proportionate and rank-based selection operators largely outperform other selection operators when it comes to evolving behavioral specialization.
\end{abstract}

\section{CCS CONCEPTS}

-Computer systems organization $\rightarrow$ Robotics; Computing methodologies $\rightarrow$ Artificial intelligence;

\section{KEYWORDS}

evolutionary robotics, embodied evolution, swarm robotics

\section{ACM Reference format:}

Nicolas Bredeche, Jean-Marc Montanier, and Simon Carrignon. 2017. Benefits of Proportionate Selection in Embodied Evolution: a Case Study with Behavioural Specialization. In Proceedings of GECCO '17 Companion, Berlin, Germany, fuly 15-19, 2017, 2 pages.

DOI: http://dx.doi.org/10.1145/3067695.3082551

\section{INTRODUCTION}

Embodied evolution (EE), as a subfield of evolutionary robotics, is dedicated to the design of distributed on-line learning algorithms for swarm/collective robotics [2,4]. One major challenge is posed by the acquisition of behavioral specialization, i.e. where two (or more) sub-parts of a group of robots can evolve different decisionmaking strategies when required. As shown in previous works, this is far from trivial and may only be achieved under very specific conditions.

In our own previous work [3], we showed that reproductive isolation plays a major role to help bootstrap and maintain more than one genotypic signature in the population.

${ }^{*}$ Corresponding author
In this paper, we extend our previous work to consider proportionate selection operators, either based on absolute fitness values (i.e. fitness proportionate selection) or relative fitness values (i.e. rank-based selection). While other selection methods are now generally preferred by the community, proportionate selection retains an interesting feature when it comes to embodied evolution: by design, these selection methods are able to maintain polymorphism (i.e. population with more than one family of genotypes) by sampling from the whole population rather than from a truncated part.

We claim, and show in the following, that proportionate selection methods offer very efficient off-the-shelf solutions to achieve behavioral specialization in embodied evolutionary robotics.

\section{METHOD}

We use the exact same method we previously described in [3] ${ }^{1}$. We provide a short summary here.Khepera-like robots are placed in a round environment where two resources can be found. Each robot may forage energy from one particular resource, but both resources must be foraged to allow the whole population to survive (i.e. each resource can only feed half the population). Foraging energy from resources serves two purposes: (1) to compute the fitness value of the robot and (2) to enable the robot to move (i.e. a robot is removed from the experiment if its energy level drops to zero).

Each robot is driven by a simple perceptron (hyperbolic tangent activation function, no hidden layer) that maps sensory inputs to two motor output neurons (left and right motor speed). Perceptron's weights are evolved, as well as a particular gene, termed $g_{s k i l l}$, that defines the capacity to synthesize energy from each resource (i.e. $g_{\text {skill }} \in[-1,+1]$, with each extreme value defining a particular ability to synthesize from one of the two resources). The rationale is that to forage energy from one resource, a robot must both stand in the area where the resource is available and to be able to synthesize energy from it (which depends on the value of $g_{s k i l l}$ ).

The evolutionary algorithms used are simplistic versions of embodied evolution, with exchange of genetic material occuring in an on-line, distributed fashion among robots which are close enough to one another. A comparaison between several selection operators was performed in our original work, including random selection (as implemented in mEDEA [1]) and performance-based selection (tournament and elitist selection operators).

We devise four experimental simulation setups, each defined by the population size considered (either 200 or 500 robots) and the position of the resources with respect to one another (the SeperateEnv environment, where resources are found in different areas, and the

$\overline{{ }^{1} \mathrm{http} / / / j o u r n a l . f r o n t i e r s i n . o r g / a r t i c l e / 10.3389 / f r o b t .2016 .00038 / f u l l ~}$ 
more challenging ColocateEnv environment, where resources are co-located). In all setups, evolutionary adaptation is expected to converge towards an equilibrium between two families of genotypes, each specialized on one resource, whether reproductive isolation is possible or not.

In this paper, we implement fitness-proportionate and rankbased selection operators. To some extent, proportionate selection operators share with random selection the propensity to sample from the whole population. They also share with other performancebased selection operators the incentive to bias selection towards better performance w.r.t. the objective function.

\section{RESULTS}

Table 1 (resp. Table 2) gives results with 200 (resp. 500) robots per population, for both environments. Each run falls in one of three categories, whether evolutionary adaptation completely failed (extinct), succeeded partly (one group, which implies only half the population was able to survive) or succeeded completely (two groups, meaning the whole population survived, with each group foraging energy from a particular resource).

\begin{tabular}{lllll}
\hline & & \multicolumn{3}{c}{ \# runs } \\
\cline { 3 - 5 } selection & environment & 2 groups & 1 group & extinct \\
\hline \hline random & separateEnv & 18 & 32 & 0 \\
\hline tournament-5 & separateEnv & 8 & 37 & 5 \\
tournament-20 & separateEnv & 3 & 35 & 12 \\
\hline elitist & separateEnv & 1 & 31 & 18 \\
\hline fitness-prop & separateEnv & $\mathbf{2 8}$ & 22 & 0 \\
rank-prop & separateEnv & 13 & 37 & 0 \\
\hline \hline random & collocateEnv & 2 & 42 & 6 \\
\hline tournament-5 & collocateEnv & 1 & 33 & 16 \\
tournament-20 & collocateEnv & 0 & 16 & 34 \\
\hline elitist & collocateEnv & 0 & 18 & 32 \\
\hline fitness-prop & collocateEnv & 1 & 44 & 5 \\
rank-prop & collocateEnv & $\mathbf{4}$ & 46 & 0 \\
\hline
\end{tabular}

Table 1: Classification of the outcome of runs with a population of 200 robots. Classes are determined using the value of the skill's gene. 50 runs per experiment. Results in bold are new, other results are taken from [3].

Results clearly show that proportionate selection methods retain the benefits of pure environment-driven selection (cf. random selection) and benefits from optimizing a user-defined objective function in even the most difficult collocateEnv environment.

This is particularly prominent when the population size is large as selection pressure (resp. genetic drift) is weaker (resp. stronger) in smaller populations. With a large population, proportionate selection methods outperform other methods by a large margin in the more difficult ColocateEnv environment, i.e. when there is no reproductive isolation to help evolve separate species in separate locations.

\begin{tabular}{lllll}
\hline \multirow{2}{*}{ selection } & environment & \multicolumn{3}{c}{ \# runs } \\
\cline { 3 - 5 } & 2 groups & 1 group & extinct \\
\hline \hline random & separateEnv & 48 & 2 & 0 \\
\hline tournament-5 & separateEnv & 38 & 12 & 0 \\
tournament-20 & separateEnv & 27 & 19 & 4 \\
\hline elitist & separateEnv & 11 & 35 & 4 \\
\hline fitness-prop & separateEnv & $\mathbf{4 9}$ & 1 & 0 \\
rank-prop & separateEnv & 44 & 6 & 0 \\
\hline \hline random & collocateEnv & 1 & 43 & 6 \\
\hline tournament-5 & collocateEnv & 4 & 35 & 11 \\
tournament-20 & collocateEnv & 0 & 26 & 24 \\
\hline elitist & collocateEnv & 0 & 30 & 20 \\
\hline fitness-prop & collocateEnv & 9 & 37 & 4 \\
rank-prop & collocateEnv & $\mathbf{1 9}$ & 31 & 0
\end{tabular}

Table 2: Classification of the outcome of runs with a population of 500 robots. Classes are determined using the value of the skill's gene. 50 runs per experiment. All results are new.

The take-home message of this paper is thus the following: proportionate selection operators are very relevant when it comes to evolve behavioural specialization, thanks to a population-wide sampling method and performance-biased selection. This message, of course, has to be considered in conjunction with previous results [3]: reproductive isolation and a large population size still play important roles in the outcome of evolutionary adaptation.

An open issue is that there is no clear distinction as to what is best between fitness-proportionate and rank-based selection methods as each excels in specific setups. Given the only difference concerns the weight given to each individual using either absolute or relative fitness values, there may be an optimal way to distribute the selection probability over the population, e.g. using a particular of non-linear rank-based fitness assignement method. But the shape of this particular function may well depend on the task and the environment at hand.

\section{ACKNOWLEDGMENT}

This work is supported by the European Union's Horizon 2020 research and innovation programme under grant agreement No.640891.

\section{REFERENCES}

[1] Nicolas Bredeche and Jean-Marc Montanier. Environment-driven embodied evolution in a population of autonomous agents. Parallel Problem Solving from Nature, PPSN XI, pages 290-299, 2010.

[2] Stephane Doncieux, Nicolas Bredeche, Jean-Baptiste Mouret, and Agoston E. (Gusz) Eiben. Evolutionary robotics: What, why, and where to. Frontiers in Robotics and AI, 2:4, 2015.

[3] Jean-Marc Montanier, Simon Carrignon, and Nicolas Bredeche. Behavioral specialization in embodied evolutionary robotics: Why so difficult? Frontiers in Robotics and AI, 3:38, 2016

[4] Richard A Watson, Sevan G Ficici, and Jordan B Pollack. Embodied evolution: Distributing an evolutionary algorithm in a population of robots. Robotics and Autonomous Systems, 39(1):1-18, 2002. 